\title{
Serum Beta HCG and uterine artery Doppler studies in second trimester to predict preeclampsia and eclampsia
}

\author{
Nitin Kulkarni*, Radhika Bansal, Pankaj Pawar
}

Department of Obstetrics and Gynecology, ACPM Medical College, Dhule, Maharashtra, India

Received: 12 March 2018

Accepted: 05 April 2018

*Correspondence:

Dr. Nitin Kulkarni,

E-mail: kulkarnink76@gmail.com

Copyright: (C) the author(s), publisher and licensee Medip Academy. This is an open-access article distributed under the terms of the Creative Commons Attribution Non-Commercial License, which permits unrestricted non-commercial use, distribution, and reproduction in any medium, provided the original work is properly cited.

\section{ABSTRACT}

Background: Hypertensive disorders during pregnancy remain amongst the most significant and intriguing unsolved problems in obstetrics. The study aims at testing the hypothesis that women with high serum beta hCG levels and alterations in waveforms in the uterine artery doppler in early second trimester have high risk of developing preeclampsia.

Methods: Serum Beta hCG estimation was done by Sandwich chemiluminescence immunoassay method. All uterine artery waveforms were obtained using a Toshiba nemio ultrasound machine attached to a $3.5 \mathrm{MHz}$ curvilinear transducer, with colour and pulsed Doppler abilities.

Results: For prediction of preeclampsia or eclampsia uterine artery Doppler velocimetry alone shows specificity of $96.30 \%$, sensitivity of $90 \%$, positive predictive value of $94 \%$ and negative predictive value of $80 \%$. When it is combined with serum beta HCG sensitivity and specificity are almost same, but alone serum beta HCG levels are showing sensitivity of $96 \%$ and specificity of just $76 \%$.

Conclusions: Abnormal waveforms on uterine Doppler studies are the better predictors for preeclampsia and eclampsia when done in early second trimester.

Keywords: Beta HCG, Doppler velocimetry, Eclampsia, Prediction of preeclampsia

\section{INTRODUCTION}

Hypertensive disorders during pregnancy remain amongst the most significant and intriguing unsolved problems in obstetrics. ${ }^{1}$ Pregnancy induced hypertension along with its sequelae that is preeclampsia and eclampsia is a unique disease seen only in pregnancy, affecting 12 to $15 \%$ of all pregnant women. ${ }^{2}$

Of all the hypertensive disorders during pregnancy, the preeclampsia syndrome, either alone or superimposed on chronic hypertension is the most dangerous. ${ }^{1}$ It is a major cause of maternal and perinatal morbidity and mortality and is thought to be predominantly as the consequence of impaired placentation. ${ }^{3-5}$ Preeclampsia can be best described as a pregnancy specific syndrome that can affect virtually every organ system and widely varies in its clinical phenotypic expression.

It can be subdivided into early onset preeclampsia, requiring delivery before 34 weeks of gestation and late onset preeclampsia with delivery at or after 34 weeks, because the former is associated with a higher incidence of adverse outcomes. ${ }^{6-9}$ It is indeed a constant endeavour of obstetricians to identify the risk of pregnancy induced hypertension or preeclampsia involved in pregnancy and if possible its prediction. Because, if prediction becomes possible prevention will follow naturally. Various attempts have been made to identify early markers of faulty placentation, impaired placental perfusion, 
endothelial cell activation and dysfunction, and activation of coagulation. Hence, measurement during early pregnancy or across pregnancy especially second trimester of various biological, biochemical, biophysical and radiological markers implicated in preeclampsia syndrome has been proposed to predict its development. But none of the tests has been accepted widely due to their low predictive value.

The abnormal placentation has been considered as one of the initial events in the disease process. ${ }^{10}$ It has been hypothesized that during mid trimester, immunological changes occur in the trophoblasts, resulting in secretory response, which is seen as a rise in the beta HCG levels.

Also, because of faulty trophoblastic invasion of the spiral arteries uteroplacental circulation remains in state of high resistance and low flow which on doppler is reflected by persisting increased impedance to flow and persistent notching. ${ }^{11}$

Hence, for our study we have tried to find out and compare the predictive value of Beta HCG levels and uterine artery Doppler velocimetry as predictors for preeclampsia.

\section{METHODS}

The study was carried out between December 2016 and November 2017

\section{Selection of cases}

A total of 100 pregnant women who attended antenatal clinics of the department of obstetrics and gynaecology of ACPM Medical College Dhule as well as those admitted in the antenatal ward were selected for the study.

\section{Inclusion criteria}

- Pregnant normotensive and non-proteinuric women selected randomly between the gestational age of 14 to 20 weeks attending the ANC clinics irrespective of parity.

- Women with multiple pregnancy, congenital malformation, essential hypertension/pregnancy induced hypertension, diabetes mellitus, molar pregnancy.

\section{Exclusion criteria}

- History of down syndrome were excluded from the study.

All the patients selected had experienced regular menstrual cycles and had precisely recorded the dates of their last menstrual periods. If menstrual history and examination findings were not correlating ultrasonography was done to find the exact period of gestation. All the patients in this study were subjected to detail history regarding age, parity, height, pre-pregnancy weight and weight at the time of blood collection was noted down. Maternal education, religion, race, socioeconomic status, family history of preeclampsia, smoking habits, medical history of first degree family members and physical activity during pregnancy were noted.

Systemic examination with special reference to edema, Blood pressure and gestational week were carried out and routine antenatal investigations were done.

Out of 120 pregnant women selected initially, 100 women who completed their pregnancies and delivered at our hospital were evaluated and statistically analysed. Definitions were used for pregnancy induced hypertension and proteinuria.

PIH was defined as systolic blood pressure of at least $140 \mathrm{mmHg}$ with a $>30 \mathrm{mmHg}$ rise and/or diastolic blood pressure of at least $90 \mathrm{mmHg}$ with a rise of $>15 \mathrm{mmHg}$ occurring on two or more occasions after 20 weeks of gestation.

Pre-eclampsia was defined as gestational hypertension and proteinuria of at least ' $2+$ ' or $1 \mathrm{~g} / \mathrm{L}$ on dipstick or 24 hour urinary protein excretion $>0.3 \mathrm{~g}$.

Estimation of serum Beta Hcg level was done by Sandwich chemiluminescence immunoassay method. The quantitative determination of chorionic gonadotropin in human serum was carried out by Microplate Immuno enzymometric assay, with kits obtained from MAGLUMI Fully- auto chemiluminescence immunoassay (CLIA) analyser (Including Maglumi 600, Maglumi 800, Maglumi 1000, Maglumi 1000 Plus, Maglumi 2000, Maglumi 2000 Plus, Maglumi 4000 and Maglumi 4000 Plus)

All uterine artery waveforms were obtained using a Toshiba nemio ultrasound machine attached to a $3.5 \mathrm{MHz}$ curvilinear transducer, with colour and pulsed Doppler abilities. The examinations were performed on patients in a semi-recumbent position after 5 minutes of rest, and the transducers were placed in a longitudinal plane along the inguinal area.

The diastolic notch was defined as the slower velocity just after systolic flow, but before maximum diastolic flow in bilateral uterine arteries.

$\mathrm{PI}=$ Peak systolic flow-least diastolic flow/Mean blood flow velocity

RI= Peak systolic flow-least diastolic flow/Peak systolic flow

S/D ratio= Ratio of systolic to diastolic velocity (measured at peak systolic and end - diastolic flows) 


\section{RESULTS}

Out of 100 cases who completed the study, 17 patients developed PIH. Mean age was 26.81 \pm 4.05 (Table 1).

Table 1: Age wise distribution of patients.

\begin{tabular}{|l|l|}
\hline Age group (in years) & No. of patients \\
\hline $20-25$ & 26 \\
\hline $26-30$ & 54 \\
\hline $30-35$ & 17 \\
\hline$>35$ & 3 \\
\hline
\end{tabular}

Baseline blood pressure at the time of inclusion in study was $110 \pm 10$ (SD) systolic and $74 \pm 14$ (SD) diastolic. Incidence of $\mathrm{PIH}$ was more when maternal serum Beta hCG level was $>2$ MOM (Table 2) and $\geq 40,000 \mathrm{mIU} / \mathrm{ml}$ (Table 3).

Table 2: Distribution of cases according to hypertensive status and HCG MOM levels.

\begin{tabular}{lllll}
$\begin{array}{l}\text { HCG } \\
\text { levels } \\
\text { (MOM) }\end{array}$ & $\begin{array}{l}\text { No. of } \\
\text { patients }\end{array}$ & Normotensive & $\begin{array}{l}\text { Mild } \\
\text { PIH }\end{array}$ & $\begin{array}{l}\text { Severe } \\
\text { PIH }\end{array}$ \\
\hline$<2$ & 84 & 80 & 03 & 01 \\
\hline$>2$ & 16 & 03 & 04 & 09 \\
\hline
\end{tabular}

Table 3: Distribution of cases according to hypertensive status and HCG levels in $\mathrm{mIU} / \mathrm{ml}$.

\begin{tabular}{|lllll|}
$\begin{array}{l}\text { Beta hCG } \\
\text { levels } \\
(\mathrm{m} / \mathrm{l} / \mathrm{ml})\end{array}$ & $\begin{array}{l}\text { No. of } \\
\text { cases }\end{array}$ & $\begin{array}{l}\text { Normotensive } \\
(\%)\end{array}$ & $\begin{array}{l}\text { Mild } \\
\text { PIH } \\
(\%)\end{array}$ & $\begin{array}{l}\text { Severe } \\
\text { PIH } \\
(\%)\end{array}$ \\
\hline$<20,000$ & 40 & 40 & 00 & 00 \\
\hline $20,000-40,000$ & 34 & 33 & 01 & 00 \\
\hline $30,000-40,000$ & 10 & 07 & 02 & 01 \\
\hline$>40,000$ & 16 & 03 & 04 & 09 \\
\hline
\end{tabular}

Table 4: comparison of results of doppler velocimetry studies with hypertensive status of patients at term.

\begin{tabular}{|lclll|}
\hline $\begin{array}{l}\text { Doppler } \\
\text { index }\end{array}$ & $\begin{array}{l}\text { No. } \\
\text { of } \\
\text { cases }\end{array}$ & $\begin{array}{l}\text { Normotensive } \\
(\%)\end{array}$ & $\begin{array}{l}\text { Mild } \\
\text { PIH } \\
(\%)\end{array}$ & $\begin{array}{l}\text { Severe } \\
\text { PIH } \\
(\%)\end{array}$ \\
\hline $\begin{array}{l}\text { PI } \leq 2.3 \text { or } \\
90^{\text {th }} \\
\text { percentile } \\
\text { RI } \geq 0.55 \text { or } \\
90^{\text {th }}\end{array}$ & 18 & 00 & 01 & 07 \\
percentile & 18 & 01 & 00 & 08 \\
\hline $\begin{array}{l}\text { Unilateral } \\
\text { notch }\end{array}$ & 16 & 01 & 00 & 08 \\
\hline $\begin{array}{l}\text { Bilateral } \\
\text { notch }\end{array}$ & 19 & 00 & 01 & 09 \\
\hline $\begin{array}{l}\text { Normal } \\
\text { doppler } \\
\text { velocimetric } \\
\text { indices }\end{array}$ & 81 & 76 & 02 & 02 \\
\hline
\end{tabular}

Out of 19 patients with abnormal uterine doppler velocimetry flow 17 developed PIH. While out of 81 patients with normal doppler study only one developed mild PIH at term (Table 4).

When uterine doppler velocimetry compared with beta hcg; doppler was showing more sensitivity as well as specificity (Table 5).

Table 5: Pooled and single estimates for uterine artery doppler (UAD) ultrasonography in predicting preeclampsia in patients.

\begin{tabular}{|lllll|}
\hline & Sensitivity & Specificity & PPV & NPV \\
\hline Beta HCG & 96 & 76 & 90 & 72 \\
\hline $\begin{array}{l}\text { UAD (RI, } \\
\begin{array}{l}\text { PI, S/D } \\
\text { ratio and } \\
\text { notching) }\end{array}\end{array}$ & 90 & 96.3 & 94 & 80 \\
\hline
\end{tabular}

\section{DISCUSSION}

Uterine artery doppler ultrasonography predicts preeclampsia. A high S/D ratio or the persistence of an early diastolic notch reflects increased peripheral vascular resistance. Specifically, an increased pulsatility index with notching in the second trimester best predicted overall pre-eclampsia in low risk and high-risk patients. An increased pulsatility index or bilateral notching best predicted severe pre- eclampsia.

Placental location is one of the key factors determining the velocity waveform. The uterine artery proximal to the placenta shows lower resistance than does the nonplacental uterine artery. This phenomenon has been attributed to the fact that the placental uterine artery perfuses the subplacental myometrium, and therefore reflects placental perfusion, whereas the non-placental uterine artery mainly perfuses the non- placental myometrium, and thus may exhibit increased peripheral resistance. This asymmetry in uteroplacental circulation is primarily explained by a significant increase in the S/D ratio values of the nonplacental uterine artery. However, the placenta usually receives its blood supply from both uterine arteries to differing degrees. In this study, the clinical utility of both unilateral and bilateral abnormalities of uterine artery doppler waveforms was assessed (disregarding placental location) as a predictor of poor pregnancy outcomes among a low-risk population. $^{12}$

Also, it was evident from our study that those pregnant women having very high serum beta HCG level around $45000 \mathrm{mIU} / \mathrm{ml}$ at the second trimester of pregnancy would develop PIH. This is consistent with the findings of several authors. ${ }^{13,14}$ Patients with overt pre-eclampsia in the third trimester had increased maternal serum beta HCG levels. This is general agreement that the Placenta remains the main source of Beta HCG in patients with preeclampsia, but whether the cause of high circulating 
levels of hormone is placental overproduction is still debated. Some advocate that hCG secretion may be increased as a consequence of abnormal placental invasion or placental immaturity. ${ }^{15}$ It may also be linked to the trophoblast response to hypoxia with the development of a hypersecretory state. ${ }^{16}$ A role of placental factors is further supported by the findings of increased lipid peroxidation and oxidation stress in placentas of women with pre-eclampsia. ${ }^{17}$ Compared with normal pregnancies, the placenta of patients with unexplained elevated maternal beta $\mathrm{HCG}$ levels in the second trimester tend to be larger and tend to have an increase density of Beta hCG positive trophoblast along with an increased intensity of Beta hCG immunostaining within the placental villi. ${ }^{18}$ Our findings suggest a very strong correlation between serum beta hCG and risk of developing PIH. The risk factors and metabolic alterations are similar in pre-eclampsia and atherosclerosis and this might suggest a common pathophysiology. Oxidative stress secondary to reduced placental perfusion leads to endothelial dysfunction, linking the two stages of the syndrome. ${ }^{19}$

So, in a proposed new approach for a more potent prenatal care of all high-risk cases, both these predictors can be used either combined or alone; as both are fairly good predictors in second trimester of impending preeclampsia and eclampsia in late pregnancy, for identifying the high-risk cases as well as the cases that will potentially benefit from prophylactic pharmacological interventions.

\section{CONCLUSION}

Based on the results of the study, pulsatility index and bilateral notching are the most promising Doppler indices to predict risk of preeclampsia and eclampsia and should be used in daily clinical practice, although the results vary according to patient risk. Doppler assessment is non -invasive and thus acceptable to patients. It is specialized, in both terms of the equipment required and the operator's expertise. In future further research should focus on combining uterine artery doppler velocimetry, serum beta hCG with other predictors like lipid profile in second trimester to achieve best predictor for preeclampsia and eclampsia so as to achieve early recognition of complications for better feto- maternal outcome.

\section{ACKNOWLEDGMENTS}

we are thankful for all staff from OBGY department, Radiology department, and Pathology department,

Special thanks to our HOD Dr. Alka Patil for her wholehearted support throughout our study.

Funding: No funding sources

Conflict of interest: None declared
Ethical approval: The study was approved by the Institutional Ethics Committee

\section{REFERENCES}

1. Cunningham, LB, Spong DH, Casey, Sheffield; Hypertensive disorders chapter 40; Williams obstetrics $24^{\text {th }}$ edition, Mc Graw Hill Education, Newyork

2. Kaur Gumandeep, Jain Vimla, Mehta Seema, Himani Sunita; Prediction of PIH by Maternal Serum Beta HCG Levels in the Second Trimester (13-20 weeks) of Pregnancy. J Obstet Gynecol India. 2012;62:32-4

3. World Health Organization, Make Every Mother and Child Count, World Health Report,2005, World Health Organization, Geneva, Switzerland; 2005

4. Confidential Enquiry into Maternal and Child Health (CEMACH), Perinatal Mortality 2006. England, Wales and Northern Ireland, CEMACH, London, UK; 2008.

5. L.Dubey, "The global impact of pre-eclampsia and eclampsia," Semi Perinatol. 2009;33:130-7.

6. Yu CK, Khouri O, Onwudiwe N, Spiliopoulos Y, Nicolaides KH. Prediction of pre-eclampsia by uterine artery Doppler imaging: relationship to gestational age at delivery and small-for-gestational age. Ultrasound Obstet and Gynecol. 2008;31:310-3.

7. Witlin AG, Saade GR, Mattar F, Sibai BM. Predictors of neonatal outcome in women with severe preeclampsia or eclampsia between 24 and 33 weeks' gestation. American J Obstet Gynecol. 2000;182:607-11.

8. Irgens HU, Roberts JM, Reisæter L, Irgens LM, Lie RT. Long term mortality of mothers and fathers after pre-eclampsia: population based cohort studyPreeclampsia and cardiovascular disease later in life: who is at risk? BMJ. 2001;323:1213-7.

9. P.von Dadelszen, L.A. Magee, and J.M. Roberts, "Subclassification of Preeclampsia," Hypertension Preg. 2003;22:143-8.

10. Hsu CD, Chan DW, Iriye B, Johnson TR, Hong SF, Repke JT. Elevated serum human chorionic gonadotropin as evidence of secretory response in severe preeclampsia. American $J$ Obstet and Gynecol. 1994;170:1135-8.

11. Woschitz MC, Idris T, Csapo B, Haas J, Ulrich D, Lang $\mathrm{U}$ and Cervar-Zivkovic M; Uterine Artery Doppler in Women with History of Previous Pre eclampsia and women with Chronic Hypertension: Re-evaluation of a prognostic Value in a High Risk Population; Gynecol Obstet. 2004;4:2.

12. Park YW, Lim JC, Kim YH, Kwon HS. Uterine artery Doppler velocimetry during mid-second trimester to predict complications of pregnancy based on unilateral or bilateral abnormalities. Yonsei medical journal. 2005;46:652-7.

13. Sorensen TK, Williams MA, Zingheim RW, Clement SJ, Hickok DE. Elevated second-trimester human chorionic gonadotropin and subsequent pregnancy- 
induced hypertension. American J Obstet Gynecol. 1993;169:834-8.

14. Gökdeniz r, Arigüloğlu E, Bazoğlu N, Balat Ö. Elevated Serumlbeta-hCG Levels in Severe Preeclampsia. Turkish J Med Sci. 2000;30:43-6.

15. Lieppman RE, Williams MA, Cheng EY, Resta R, Zingheim R, Hickok DE et al.,. An association between elevated levels of human chorionic gonadotropin in the midtrimester and adverse pregnancy outcome. American journal of obstetrics and gynecology. 1993;168:1852-6.

16. Hsu CD, Chan DW, Iriye B, Johnson TR, Hong SF, Repke JT. Elevated serum human chorionic gonadotropin as evidence of secretory response in severe preeclampsia. American J Obstet Gynecol. 1994;170:1135-8.
17. Myatt L, Miodovnik M. Prediction of pre-eclampsia. Semin Perinatol. 1999;23:45-57.

18. Liu DF, Dickerman LH, Redline RW. Pathological findings in pregnancies with unexplained increase in mid trimester maternal serum human chorionic gonadotropin levels. Am J Clin Pathol. 1999; 111:209-15.

19. Robert JM. Pre eclampsia: what we know and what we do not know. Semin Perinatol. 2000;24:24-8.

Cite this article as: Kulkarni N, Bansal R, Pawar P. Serum Beta HCG and uterine artery Doppler studies in second trimester to predict preeclampsia and eclampsia. Int J Reprod Contracept Obstet Gynecol 2018;7:1924-8. 